\title{
Preliminary study on the effects of photo traps used to monitor Mediterranean monk seals Monachus monachus
}

\author{
Ali Cemal Gucu* \\ Middle East Technical University Institute of Marine Sciences, PO Box 28, Erdemli 33731, Mersin, Turkey
}

\begin{abstract}
I evaluate the possible deterrent effect of visual-flash photo traps used to monitor Mediterranean monk seals Monachus monachus in their caves. Two systems of photo trapping were deployed in a cave, one using a flashing visible light and the other using an infrared light source. These systems were used alternately, each for an average duration of $1 \mathrm{wk}$ at a time. A total of 453 digital photographs were taken by the photo traps throughout the experiment, which was conducted from July 2007 to February 2008. Based on an analysis of these photographs, 4 individuals of different age classes were identified. The individuals monitored never displayed an escape response following the flash; although some briefly responded to the flash, they quickly resumed their resting behaviour. Analysis of 47 haul-out events indicated that the average haul-out time of seals repeatedly exposed to a visible flash is longer than that of seals exposed to infrared flash. Although the small sample size limits conclusions, the striking difference found between haul-out times may be a sign of a negative effect which influences resting time of individuals.
\end{abstract}

KEY WORDS: Breeding caves - Disturbance - Infra-red cameras - Mediterranean monk seal · Monachus monachus · Turkey · Visual-flash photo traps

\section{INTRODUCTION}

The size of the Mediterranean monk seal Monachus monachus population is currently estimated to be in the hundreds (RAC/SPA 2005). Studying this species is extremely difficult because in addition to its rarity, its behaviour is elusive. Due to its critical population status, the methods used to study this species should be selected in order to minimise disturbance. One way of obtaining population estimates is to monitor the animals' resting and breeding caves. However, human contact with seals in a cave may significantly disturb the animals. Inexpensive photo traps deployed over long time spans at frequently visited caves provide an option for monitoring the number of individuals and demographic patterns. Hiby \& Jeffery (1987) were the first field researchers to adopt remotely trig- gered cameras for Mediterranean monk seal markrecapture estimates. This technique has since been used to monitor the monk seal colony on the eastern Mediterranean (Mo et al. 2001, Gucu et al. 2004, 2009b, Dendrinos et al. 2007) and Atlantic coasts (Layna et al. 1999, Forcada \& Aguilar 2006). The photographs obtained by the photo traps can be used to identify the individuals (Gucu et al. 2009a,b). Thus, the use of colour images in seal photo-identification, only attainable in dark caves by flash-assisted photography, has great advantages over infrared images, in which the details, such as scars and discolorations, are less visible.

Modern photo traps have detectors that trigger the camera. Some cameras incorporate an infrared light source (invisible to the seals), while others use a builtin flash sufficient to illuminate a range of up to $7 \mathrm{~m}$ in 
total darkness. The photo-trap experiments carried out on the Greek Island of Kefalonia provided no evidence of reaction by seals to the camera flash (Hiby \& Jeffery 1987). However, the authors noted that photographs showing a fright reaction would not be expected because of the delay between successive photographs. Hence, the question remains whether use of photo traps with flash disturbs monk seals in their resting habitat (and whether their use might even deter use of that habitat). This study is a preliminary attempt to evaluate the level of disturbance produced by flashing photo traps.

\section{MATERIALS AND METHODS}

The study was performed in a cave located near Mersin on the southern coast of Turkey. Two photo traps, one with flash (Vigil P-Box D-435, Circuitronique Estrie) and the other with an infrared light source (Moultrie MFH-DGS-I40, EBSCO Industries), were alternatively deployed for a total of $2682 \mathrm{~h}$ between July 2007 and February 2008. To avoid possible biases caused by physiological changes such as moulting, reproductive status, etc., which might alter the animals' resting demands, the photo traps were continuously alternated. The average camera use time was $1 \mathrm{wk}$, and the cameras were changed only when there was no seal activity in the cave. If seals were present at the time of a scheduled camera change, the photo trap was left in place for another week. It is assumed that infrared light is not sensed by the seals (Lavigne \& Ronald 1975) and therefore would not affect the animals' haul-out behaviour. Impact of flash was evaluated on the basis of changes in the haul-out pattern when seals were exposed to flash or infrared photography.

The infrared camera was deployed 9 times (1508 h total) and the photo trap with flash was used 7 times (1174 h total) throughout the experiment. The cameras were set to a delay of $10 \mathrm{~min}$. In addition to the data collected during the experiment some of the author's unpublished data that had been collected using different delay modes were also used to compare the flashing frequency and the haul-out time. Successive photographs of a seal were assumed to represent a haul-out. The haul-out duration was estimated as the time difference between the first and the last photographs of a haul-out. Changes in the colour of the skin in flash photography were also used to determine the beginning and end of a haul-out event; the skin is darker and shiny when a seal comes out of the water and gradually turns pale grey as it dries. The photographed seals were grouped according to their sex and approximate age (cf. Samaranch \& González
2000). Later, morphological irregularities, such as scars on the body were plotted on a scar chart, enabling identification of each individual.

A 2-level nested ANOVA with replications (Sokal \& Rohlf 1995) was used to compare the haul-out times of groups of individuals exposed to flash and infrared. This test takes into account the variances of haul-outs between the 2 photo-trap systems (groups), between the individuals within each group (subgroups) and multiple haul-out estimates per individual (error). The differences in means of 2 groups were graphically presented with $95 \%$ CI. Additionally, an infrared video camera connected to a monitor via a $100 \mathrm{~m}$ coaxial cable and an infrared light source was used to observe the reaction of the seals when the photo traps were activated. The monitor was hidden outside the cave and was visible neither from the sea nor from the cave.

\section{RESULTS}

A total of 453 digital photographs were obtained during the study. Based on these photographs, 4 individuals were identified (Table 1). In several cases an animal was photographed in an alerted posture, its head extended or directed toward the camera (Fig. 1). However, the video observations of the seals exposed to the flash indicated that seals reacted only briefly to the visible flash, especially to the first few flashings, but that the animals did not display panic escape or an immediate return into the sea after a flash. This experiment assumes that the Mediterranean monk seal is insensitive to infrared; however in some infrared images the seals reacted to the triggering of the infrared bulbs in the same manner as to the visible flash.

It was estimated that the individuals represented 47 resting haul-out events throughout the experiment (Table 2). Although no immediate return was observed during video surveillance, evaluation of the haul-outs during flash photography indicated that in 14 cases (40\% of all visits), the individual returned to the sea within $10 \mathrm{~min}$ of the first flash (Table 2). Such short haul-outs occurred 26 times (47\%) during infrared pho-

Table 1. Monachus monachus. Number of photographs obtained for each of the photo-identified seals. Note that in some cases 2 or more seals were photographed together

\begin{tabular}{|lcccc|}
\hline Code & Sex & Stage & Flash photos & Infrared photos \\
\hline F1 & Female & Adult & 84 & 114 \\
F2 & Female & Adult & 25 & 123 \\
M1 & Male & Sub-adult & 44 & 11 \\
J1 & Female & Juvenile & 129 & 110 \\
Total & & & 246 & 207 \\
\hline
\end{tabular}


Table 2. Monachus monachus. Estimated haul-out times (in min) for seals from Table 1 per individual per photo trap using visible flash and infrared photography. 'Haul-outs' refers to $10 \mathrm{~min}$ or more out of the water; 'short haul-outs' refers to less than 10 min out of the water (see 'Results' for details)

\begin{tabular}{|c|c|c|c|c|c|}
\hline Individual & Mean & $\mathrm{SD}$ & Max & $\begin{array}{c}\text { No. of } \\
\text { haul-outs }\end{array}$ & $\begin{array}{l}\text { No. of short } \\
\text { haul-outs }\end{array}$ \\
\hline \multicolumn{6}{|l|}{ Flash } \\
\hline F1 & 645 & 568 & 1516 & 7 & 3 \\
\hline $\mathrm{F} 2$ & 232 & 143 & 392 & 3 & - \\
\hline M1 & 188 & 154 & 392 & 4 & 4 \\
\hline $\mathrm{J} 1$ & 684 & 711 & 1683 & 10 & 4 \\
\hline All & 534 & 557 & 1683 & 21 & 14 \\
\hline \multicolumn{6}{|l|}{ Infrared } \\
\hline $\mathrm{F} 1$ & 226 & 181 & 669 & 16 & 7 \\
\hline $\mathrm{F} 2$ & 305 & 270 & 744 & 14 & 9 \\
\hline M1 & 97 & 66 & 151 & 3 & 2 \\
\hline $\mathrm{J} 1$ & 280 & 242 & 744 & 16 & 8 \\
\hline All & 259 & 227 & 744 & 26 & 23 \\
\hline
\end{tabular}

tography. In longer haul-outs, typically once a haul-out was over, the individuals returned to the cave within $24 \mathrm{~h}$. After a series of such successive haul-out events, the seal disappeared for a period longer than $2 \mathrm{~d}$.

The average haul-out times estimated for each individual and the variations between different photo traps are depicted in Fig. 2. When the flash was used, seals F1 and J1 stayed much longer on the haul-out platform than the other individuals, and the variations between haul-out times of these 2 individuals were the highest (Fig. 2). Seals F1 and J1 used the cave throughout the

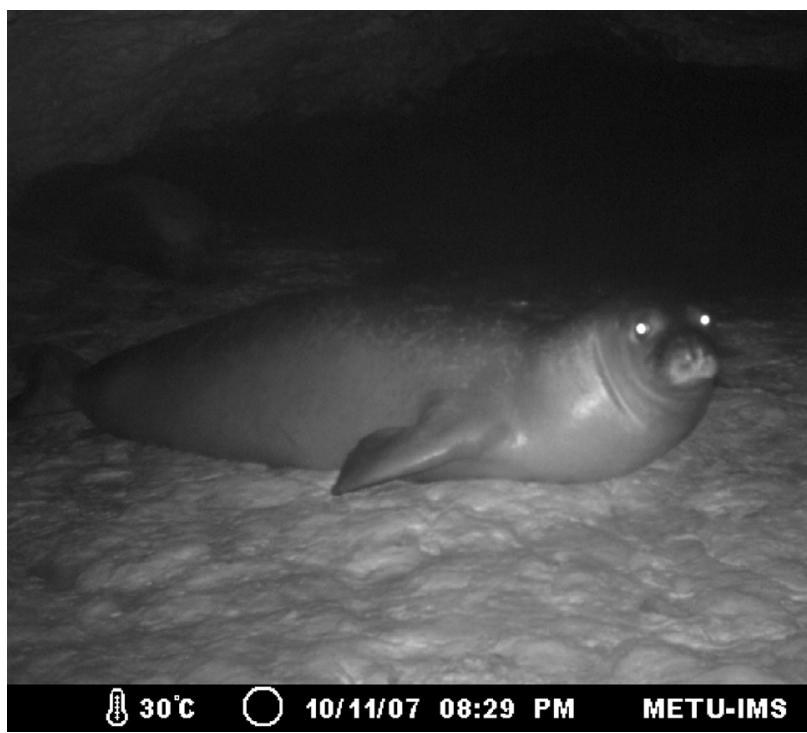

Fig. 1. Monachus monachus. Mediterranean monk seal appearing to react to the flash from the infrared camera. See 'Results' for details

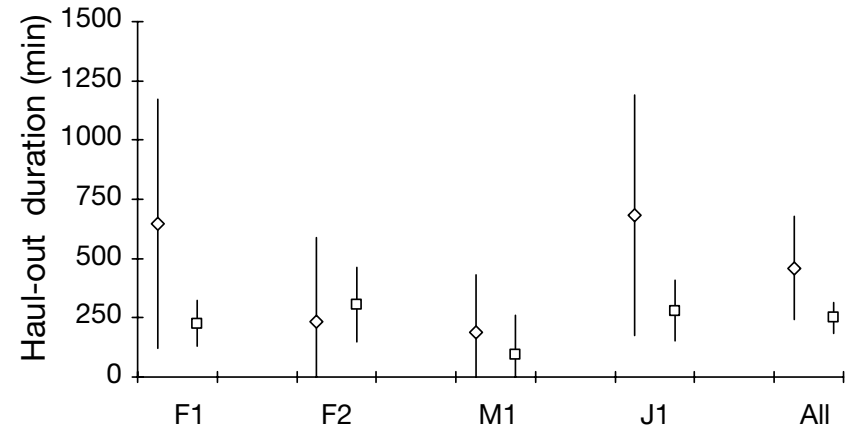

Fig. 2. Monachus monachus. Average haul-out time and $95 \%$ CI of 4 individuals identified with photo traps using a visible $(\diamond)$ and infrared $(\square)$ flash during repeated visits to the study site (females F1 \& F2, male M1 and juvenile J1)

experiment, while seals F2 and M1 were sighted for a shorter period only.

The haul-out times were compared using nested ANOVA (with haul-out time of all identified individuals nested within 2 photo-trapping methods). The test showed that the difference between subgroups (individuals) within groups (photo traps) is not significant, while there is a significant difference among the haul-out times estimated using 2 different photo traps (Table 3). Overall, the mean haul-out time of seals exposed to flash is twice as long as those estimated during infrared surveillance (Table 2). With the nested design, $17.8 \%$ of the variance is attributed to the different photo traps used and $4.2 \%$ is credited to variation between groups of individuals within photo trap types. The highest percentage of variance is observed within individuals (Table 3 ).

\section{DISCUSSION}

The mobility of seals on land is restricted, making them vulnerable at their haul-outs. Therefore, seals resting in a cave are easily alarmed and tend to return to the sea at the smallest disturbance. A flash is an abrupt change in the cave's environment that can lead to several different changes in animal behaviour. The level of disturbance by a flash may cause a seal to abandon the haul-out platform, possibly never to return to that cave. If so, the consequences of phototrap use would be catastrophic, given the limited number of suitable caves and their importance for the distribution and reproductive success of the species (Gucu et al. 2004). Hiby \& Jeffery (1987) discussed the risk of disturbance when artificial illumination is used at haul-out sites and pointed out that at least some seals photo trapped in their experiment were unaffected by the flash, as they were not dissuaded from hauling out. The present study demonstrates that the flash is recognised by the seals; however, the individu- 
Table 3. Monachus monachus. Summary of comparisons of haul-out time for 4 individuals estimated using a photo trap with visible flash vs. photo trap with infrared camera based on nested ANOVA. ${ }^{*} p=0.05$

\begin{tabular}{|lcccccc|}
\hline & $\begin{array}{c}\text { Sum of } \\
\text { squares }\end{array}$ & df & $\begin{array}{c}\text { Mean } \\
\text { square }\end{array}$ & $F$ & p & $\begin{array}{c}\text { Variance } \\
\text { (percentage) }\end{array}$ \\
\hline $\begin{array}{c}\text { Among photo-trap } \\
\text { types }\end{array}$ & $1.22 \times 10^{6}$ & 1 & $1.22 \times 10^{6}$ & 6.094 & $0.0485^{*}$ & 17.8 \\
$\begin{array}{c}\text { Individuals within } \\
\text { photo-trap types }\end{array}$ & $1.20 \times 10^{6}$ & 6 & $2.00 \times 10^{5}$ & 1.456 & 0.2074 & 4.2 \\
$\begin{array}{l}\text { Within individuals } \\
\text { Total }\end{array}$ & $8.92 \times 10^{6}$ & 65 & $1.37 \times 10^{5}$ & & & 78.0 \\
\hline
\end{tabular}

because seals are repeatedly awakened by the camera's periodic flashing. If this is true, then the frequency of flashing should have some consequences on the resting time. The differences I observed in haul-out between 2 different seals (author's unpubl. data) are summarised in Table 4. In the first case, the delay between 2 flashes was set to $30 \mathrm{~min}$ in the first deployment. A juvenile seal used the cave and presented 2 identical haulouts. After the first deployment, the camera delay was changed to $10 \mathrm{~min}$.

als observed in the experiment almost always resumed resting. There were a number of cases in which the animal was photographed only once. This may indicate that the seal had returned to the sea before the camera was re-activated after $10 \mathrm{~min}$. According to Hiby \& Jeffery (1987), seals visit this cave to check for presence of other seals, as well as to rest. Therefore, such short haul-outs could hardly be linked to the disturbance by the flashes.

Another possible risk the photo traps may pose is that, although a seal will not flee from the flash during a haul-out, it may still change its resting cave to avoid an eventual disturbance for its next haul-out. Frequently, recurring visits by individuals during the experiment showed that this is not a matter of concern. Yet, the results obtained in this experiment characterise a cave-use pattern: frequent resting visits followed by a long period of absence, which may indicate a foraging trip. This pattern agrees with direct observations (Gucu et al. 2004). The same pattern was repeated in both monitoring systems, signifying that using different photo traps has no impact on the resting pattern.

Nevertheless, when the average haul-out times with infrared and flash photography were compared, significant differences were found: the average haul-out was twice as long when visible flash was used. The nested-design ANOVA did not find a statistical difference between subgroups (Table 3). This is due to a very high variance component within subgroups, which indicates that the time spent for resting varied remarkably. The variation in resting time was highest in the individuals who used the cave for a longer period. The experiment covered 3 seasons, and the 2 animals that displayed inconsistent resting times (F1 and J1) were monitored throughout the study. Therefore this inconsistency may be due partly to seasonal changes in the physiological state and resting demand of an individual. On the other hand, seals require a certain amount of rest between foraging trips. So, it is also possible that flash photography extends haul-out times
The haul-out time of the same individual increased remarkably. In the second case, the camera delay was initially set to $60 \mathrm{~min}$. A young female used the cave. Later, the camera delay was reduced to $1 \mathrm{~min}$. The same individual presented a very long haul-out time. These changes in the haul-out durations may also explain why the seals stayed longer on the haul-out platform when they were exposed to flash photography.

\section{CONCLUSION}

Use of photo traps in haul-out caves is a vital tool in Mediterranean monk seal research. However, the reaction of a seal to the flash of the photo traps is a matter of concern, since the critical importance of this limited habitat demands that any intrusion be avoided. In this study, it was observed that the seals reacted to both types of photo trap. However, all the seals that visited the cave and were periodically exposed to a flash remained on the haul-out site and repeatedly returned to the cave. Although the seals' reactions to the photo traps were brief, the question of how these reactions influence the overall resting behaviour of the individuals could not be answered conclusively, due to limited data. Significant variations in the resting times and the relation between flash interval and the resting time should be investigated in order to minimise dis-

Table 4. Monachus monachus. Supplementary haul-out data based on author's previously unpublished data

\begin{tabular}{|lccccc|}
\hline Case & Sex & Age & $\begin{array}{c}\text { Camera } \\
\text { delay (min) }\end{array}$ & $\begin{array}{c}\text { Haul-out } \\
\text { date }\end{array}$ & $\begin{array}{c}\text { Time } \\
(\mathrm{min})\end{array}$ \\
\hline 1 & Male & Juvenile & 30 & 20 July 2008 & 996 \\
& & & 30 & 22 July 2008 & 987 \\
& & & 10 & 06 Sept 2008 & 1292 \\
2 & Female & Adult & 60 & 22 May 2005 & 396 \\
& & & 1 & 20 June 2005 & 3668 \\
\hline
\end{tabular}


turbance when using photo traps. Further, this experiment was conducted to investigate impact of photo traps on resting behaviour only; potential impacts on reproductive behaviour require further study.

Acknowledgements. This research was carried out during a project funded by the Turkish Scientific and Technical Research Council, TUBITAK (Project No: TBAG-106T166). The author thanks the members of LEVANT Nature Conservation Society (S. Sakinan and M. Ok in particular) who helped a lot in the field; thanks also go to G. Mo of ICRAM for commenting on this study.

\section{LITERATURE CITED}

Dendrinos P, Tounta E, Karamanlidis AA, Legakis A, Kotomatas S (2007) A video surveillance system for monitoring the endangered Mediterranean monk seal (Monachus monachus). Aquat Mamm 33:179-184

Forcada J, Aguilar A (2000) Use of photographic identification in capture-recapture studies of Mediterranean monk seals. Mar Mamm Sci 16:767-793

- Gucu AC, Gucu G, Orek H (2004) Habitat use and preliminary demographic evaluation of the critically endangered Mediterranean monk seal (Monachus monachus) in the Cilician Basin (Eastern Mediterranean). Biol Conserv 116:417-431

Gucu AC, Ok M, Sakinan S (2009a) A survey on the critically endangered Mediterranean monk seal, Monachus

Editorial responsibility: Jason Matthiopoulos, St. Andrews, UK monachus (Hermann, 1779) inhabiting the coast of Northern Cyprus. Isr J Ecol Evol 55:77-82

Gucu AC, Sakinan S, Ok M (2009b) Occurrence of the critically endangered Mediterranean monk seal, Monachus monachus (Hermann, 1779), at Olympos-Beyda lar National Park, Turkey. Zool Middle East 4:3-8

Hiby AR, Jeffery JS (1987) Census techniques for small populations, with special reference to the Mediterranean monk seal. Symposium of the Zoological Society of London 58: 193-210

> Lavigne DM, Ronald K (1975) Pinniped visual pigments. Comp Biochem Physiol B 52:325-329

> Layna JE, Cedenilla MA, Aparicio F, Gonzalez LM (1999) Observations of parturition in the Mediterranean monk seal (Monachus monachus). Mar Mamm Sci 15:879-882

Mo G, Gücüsoy H, Savas Y, Sigismondi C (2001) Pilot study on the use of infrared-sensitive video cameras for continuous monitoring of caves used by Mediterranean monk seal, Monachus monachus. Mammalia 65:383-386

RAC/SPA (Regional Activity Centre/Specially Protected Areas) (2005) Evaluation of the Mediterranean monk seal status. Meeting of MAP Focal Points, Athens (Greece), 21-24 September 2005. UNEP/MAP, UNEP(DEC)/MED WG.270/ Inf.22: 1-7, available at www.monachus-guardian.org/ library/rac_spa05c.pdf

Samaranch R, González LM (2000) Changes in morphology with age in Mediterranean monk seals (Monachus monachus). Mar Mamm Sci 16:141-157

Sokal RR, Rohlf FJ (1995) Biometry: the principles and practice of statistics in biological research, 3rd edn. W. H. Freeman \& Co., New York

Submitted: September 22, 2008; Accepted: April 27, 2009

Proofs received from author(s): August 6, 2009 